\title{
Small molecule activators of pre-mRNA 3' cleavage
}

\author{
KEVIN RYAN, ${ }^{1,2}$ ASYA KHLEBORODOVA, ${ }^{1,2}$ JINGYI PAN, ${ }^{1,2}$ and XIAOZHOU P. RYAN ${ }^{1,2}$ \\ ${ }^{1}$ Department of Chemistry and Biochemistry, City College of New York, New York, New York 10031, USA \\ ${ }^{2}$ Graduate Center, City University of New York, New York, New York 10031, USA
}

\begin{abstract}
$3^{\prime}$ Cleavage and polyadenylation are obligatory steps in the biogenesis of most mammalian pre-mRNAs. In vitro reconstitution of the $3^{\prime}$ cleavage reaction from human cleavage factors requires high concentrations of creatine phosphate (CP), though how $\mathrm{CP}$ activates cleavage is not known. Previously, we proposed that $\mathrm{CP}$ might work by competitively inhibiting a cleavagesuppressing serine/threonine (S/T) phosphatase. Here we show that fluoride/EDTA, a general S/T phosphatase inhibitor, activates in vitro cleavage in place of CP. Subsequent testing of inhibitors specific for different $\mathrm{S} / \mathrm{T}$ phosphatases showed that inhibitors of the PPM family of S/T phosphatases, which includes PP2C, but not the PPP family, which includes PP1, PP2A, and PP2B, activated $3^{\prime}$ cleavage in vitro. In particular, $\mathrm{NCI} 83633$, an inhibitor of PP2C, activated extensive $3^{\prime}$ cleavage at a concentration 50 -fold below that required by fluoride or $\mathrm{CP}$. The testing of structural analogs led to the identification of a more potent compound that activated 3' cleavage at $200 \mu \mathrm{M}$. While testing CP analogs to understand the origin of its cleavage activation effect, we found phosphocholine to be a more effective activator than CP. The minimal structural determinants of $3^{\prime}$ cleavage activation by phosphocholine were identified. Our results describe a much improved small molecule activator of in vitro pre-mRNA cleavage, identify the molecular determinants of cleavage activation by phosphoamines such as phosphocholine, and suggest that a PPM family phosphatase is involved in the negative regulation of mammalian pre-mRNA 3' cleavage.
\end{abstract}

Keywords: 3' end formation; RNA processing; chemical biology; protein phosphatase; PP2C

\section{INTRODUCTION}

Nearly all eukaryotic protein coding RNA transcripts are cleaved and polyadenylated at the poly(A) site during the $3^{\prime}$ end formation step of mRNA biogenesis (Zhao et al. 1999; Mandel et al. 2007). In mammalian cells, a large group of protein factors cooperates to bring about the hydrolytic $3^{\prime}$ cleavage step, which ultimately defines the end of the $3^{\prime}$ untranslated region ( $3^{\prime}$ UTR) and the start of the poly(A) tail. These proteins include four multisubunit $3^{\prime}$ cleavage factors known to be essential for the cleavage reaction: cleavage polyadenylation specificity factor (CPSF), which includes the recently identified ribonuclease CPSF-73 (Mandel et al. 2006), cleavage stimulation factor (CstF), cleavage factor I (CFIm), and cleavage factor II (CFIIm). Overall, at least 12 protein subunits are required for 3' cleavage (Mandel et al. 2007).

The in vivo $3^{\prime}$ cleavage reaction appears to take place cotranscriptionally, i.e., while RNA polymerase II ( $\mathrm{Pol}$ II) is

Reprint requests to: Kevin Ryan, Department of Chemistry and Biochemistry, City College of New York, 160 Convent Avenue, Chemistry MR-1024, New York, NY 10031, USA; e-mail: kr107@sci.ccny.cuny.edu; fax: (212) 650-6107.

Article published online ahead of print. Article and publication date are at http://www.rnajournal.org/cgi/doi/10.1261/rna.1262509. still engaged in a ternary complex with the DNA and nascent RNA (Bentley 2002; Neugebauer 2002), and several of the $3^{\prime}$ cleavage factors are carried in the elongation complex (Dantonel et al. 1997; Venkataraman et al. 2005; Glover-Cutter et al. 2008). However, it has long been known that the $3^{\prime}$ cleavage reaction can be reconstituted in the absence of transcription using cleavage factors supplied by HeLa nuclear extract (Moore and Sharp 1985) or fractionated from it (Gilmartin et al. 1988; Takagaki et al. 1989). Creatine phosphate (CP), a naturally occurring phosphagen, was initially included in the reconstituted reaction for the intended purpose of maintaining the ATP pool (Moore and Sharp 1985; Takagaki et al. 1988), but it was later found that ATP is not required for cleavage by mammalian cleavage factors (Hirose and Manley 1997). Nevertheless, for reasons that remain unclear, CP is required at a concentration of $20-60 \mathrm{mM}$ for efficient in vitro 3' cleavage (Hirose and Manley 1997). We recently proposed that, by virtue of its phosphorylated amino acid-like structure, CP might act by competitively inhibiting a cleavage-suppressing protein phosphatase (Ryan 2007). Testing this hypothesis led us to find that dephosphorylating nuclear extract with serine/threonine (S/T) phosphatases prior to CP addition sharply inhibited in vitro $3^{\prime}$ cleavage activity, while a representative tyrosine 
phosphatase had no effect. Using partially purified cleavage factors we traced the susceptibility to phosphatase treatment to a HeLa nuclear extract fraction containing CFIm and CFIIm. These results are consistent with the idea that one of the CFIm/CFIIm subunits requires $\mathrm{S} / \mathrm{T}$ phosphorylation in order to carry out its cleavage function and that pre-mRNA 3 ' cleavage may be regulated by a kinase/ phosphatase pair.

The hypothesis that a phosphatase may act to suppress $3^{\prime}$ cleavage activity led us to consider a model in which the putative phosphatase activity might be triggered-and cleavage suppressed-when the pre-cleavage complex forms on an inauthentic RNA sequence, such as may occur during the transcription of cryptic poly(A)-like sites upstream of the 3' UTR (Ryan and Bauer 2008), or in other inauthentic contexts, such as in vitro. Cryptic sites, which resemble true 3' UTR poly(A) signals and occasionally occur in transcription units (Glusman et al. 2006), must be bypassed without triggering cleavage in order for the transcript to be completed, but how their cleavage is suppressed is not known. The inauthentic context of in vitro reconstitution should, by our model, lead to inefficient processing unless a suitable phosphatase inhibitor is present to maintain cleavage factor phosphorylation. Several of the cleavage factor subunits, including those of CFI/ IIm, are known to undergo phosphorylation (Ryan and Bauer 2008), but it is not feasible, due to the small amounts of cleavage factors involved, to test this model directly by examining their phosphorylation status during in vitro cleavage. Instead, we have tested a variety of known phosphatase inhibitors for the ability to activate $3^{\prime}$ processing in vitro. We report here two structurally dissimilar small-molecule phosphatase inhibitors that activate in vitro $3^{\prime}$ cleavage: fluoride, a general $\mathrm{S} / \mathrm{T}$ phosphatase inhibitor, and NCI 83633, an inhibitor of PP2C, a PPM family S/T phosphatase. The $3^{\prime}$ cleavage-activating property of these two compounds suggests that a PPM family protein phosphatase may negatively regulate 3 ' cleavage.

\section{RESULTS}

\section{Fluoride, a general serine/threonine phosphatase inhibitor, activates $3^{\prime}$ cleavage}

To investigate the possibility that $\mathrm{CP}$ activates in vitro premRNA 3' cleavage through inhibition of an unknown phosphatase, we replaced CP with a variety of nonspecific phosphatase inhibitors in the reconstituted $3^{\prime}$ cleavage assay. In this assay, a uniformly ${ }^{32} \mathrm{P}$-labeled RNA containing the SV40L poly(A) signals is mixed with DEAEfractionated CPSF, CstF, and CFm (unseparated CFIm and CFIIm) activities (Gilmartin et al. 1988; Takagaki et al. 1989; Ryan 2007). In the absence of CP, no RNA cleavage takes place (Fig. 1A, lane 2). In the presence of $\mathrm{CP}$, a portion of the RNA is cleaved into a larger $5^{\prime}$ fragment

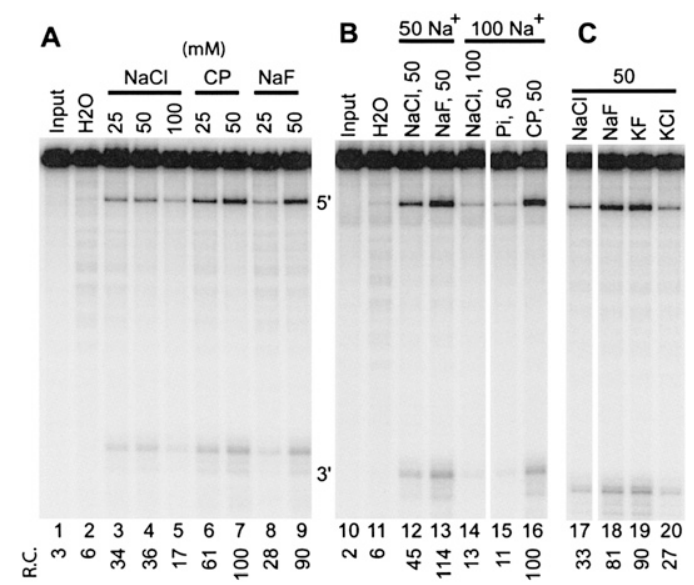

D

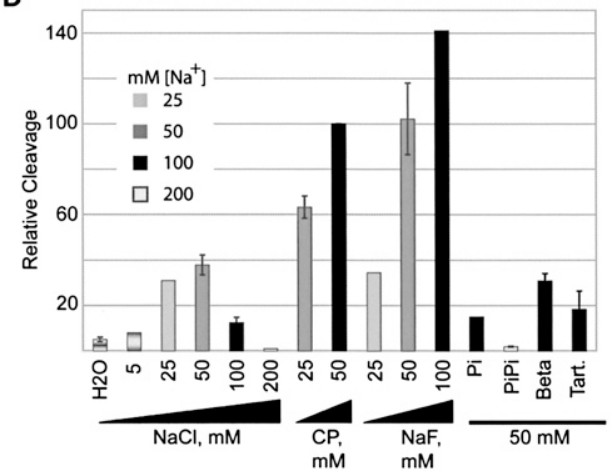

FIGURE 1. In vitro $3^{\prime}$ cleavage activation by fluoride, a general $\mathrm{S} / \mathrm{T}$ protein phosphatase inhibitor. In vitro transcribed pre-mRNA containing the SV40L polyadenylation signals was processed by combining DEAE-fractionated CPSF, CstF, and CFm. 5' and $3^{\prime}$ indicate the upstream and downstream fragments, respectively. Numbers beneath gel lane numbers indicate relative cleavage (R.C.), as defined in Materials and Methods. (A) A representative cleavage reaction with activation by $\mathrm{NaCl}, \mathrm{CP}$, and fluoride at increasing concentrations (all millimolar). (B) A representative cleavage reaction with activators grouped according to constant sodium content. $(C)$ Cleavage activation depends on fluoride, not the counterion used. (D) Quantitative summary of several cleavage activation experiments. Bars shaded according to total $\mathrm{Na}^{+}$concentration. (Beta) $\beta$-phosphoglycerol; (Tart) tartrate; (Pi) phosphate; (PiPi) pyrophosphate. All reactions were done either twice (averages shown, no error bars) or three or more times (with error bars shown to indicated $\pm 1 \mathrm{SD}$ ). Cleavage activation in all individual experiments was normalized before averaging by assigning a R.C. of $100 \%$ to cleavage by $50 \mathrm{mM} \mathrm{CP}$.

and a smaller $3^{\prime}$ fragment, which are resolved by electrophoresis (Fig. 1A, lane 7). Polyadenylation of the 5' fragment by PAP, which cofractionates with CstF in our fractionation (de Vries et al. 2000), is suppressed by including EDTA and an ATP chain terminator analog such as $2^{\prime}$ - or $3^{\prime}$-dATP.

Sodium fluoride $(\mathrm{NaF})$, a general $\mathrm{S} / \mathrm{T}$ protein phosphatase inhibitor when used with EDTA (Foulkes et al. 1983; Brautigan and Shriner 1988), was compared to CP (disodium salt). At $50 \mathrm{mM}, \mathrm{NaF}$ was as effective as $\mathrm{CP}$ at 
stimulating 3' cleavage (Fig. 1A,D). Since the sodium stoichiometry of the two activators is different, we tested $\mathrm{NaCl}$ to control for a possible $\mathrm{Na}^{+}$effect. The reconstituted cleavage reaction proved to have a complex sodium dependence (Fig. 1A,D). In the absence of CP, background cleavage increased as $\mathrm{Na}^{+}$was raised from 0 to $50 \mathrm{mM}$, but declined when $\mathrm{Na}^{+}$was raised further (Fig. 1D). When the sodium effect was taken into account, $\mathrm{NaF}$ was found to be a genuine $3^{\prime}$ cleavage activator at $50 \mathrm{mM}$, activating cleavage to almost the same extent as $50 \mathrm{mM}$ CP. However, the fraction of cleavage activation that might be attributable to the sodium in $50 \mathrm{mM} \mathrm{CP} \bullet \mathrm{Na}_{2}$, i.e., $\left[\mathrm{Na}^{+}\right]=100 \mathrm{mM}$, is smaller than that in $50 \mathrm{mM} \mathrm{NaF}$, i.e., $\left[\mathrm{Na}^{+}\right]=50 \mathrm{mM}$, making CP a slightly better cleavage activator at $50 \mathrm{mM}$ when corrected for $\mathrm{Na}^{+}$. CP is known to reach maximum activation at $60 \mathrm{mM}$, beyond which it inhibits cleavage (Hirose and Manley 1997). We found fluoride continued to stimulate the reaction when raised from 50 to $100 \mathrm{mM}$ (Fig. 1D), where any effect attributable to $\mathrm{Na}^{+}$has become smaller $\left(\left[\mathrm{Na}^{+}\right]=100 \mathrm{mM}\right)$. Thus, above $60 \mathrm{mM}$, fluoride activates cleavage better than $\mathrm{CP}$. The divergent dose response patterns of $\mathrm{NaF}$ and $\mathrm{NaCl}$ ensure that cleavage activation is indeed due to fluoride, not sodium. Using $\mathrm{KF}$ as the source of fluoride confirmed this finding (Fig. 1C).

We assayed other nonspecific phosphatase inhibitors (Fig. 1B,D). L-(+)-tartrate $\mathrm{Na}_{2}$, a protein tyrosine- and acid-phosphatase inhibitor (Zollner 1999; Shenolikar 2001), did not activate cleavage beyond that attributable to its sodium content (Fig. 1D). Orthophosphate $\mathrm{Na}_{2}$, an acid and alkaline phosphatase inhibitor (Zollner 1999) previously observed to activate a low level of 3 ' cleavage (Hirose and Manley 1997), and pyrophosphate $\mathrm{Na}_{4}$, a commonly used alkaline phosphatase inhibitor (Zollner 1999), also failed to activate cleavage beyond what could be caused by their sodium content. Only $\beta$-phosphoglycerol• $\mathrm{Na}_{2}$, (beta), a general alkaline phosphatase inhibitor (Zollner 1999), had a sodium-independent effect, but it was very weak (Fig. 1D). Thus, among the nonspecific phosphatase inhibitors tried, only the general S/T phosphatase inhibitor activated significant $3^{\prime}$ cleavage. This result is consistent with our previous finding that S/T dephosphorylation of HeLa nuclear extract or the DEAE-fractionated cleavage factors inhibits the in vitro 3' cleavage reaction (Ryan 2007).

\section{Inhibitors of a PPM family phosphatase can activate 3 ' cleavage}

Most S/T phosphatases can be classified by catalytic subunit sequence homology into three superfamilies (Moorhead et al. 2007): the phosphoprotein phosphatase (PPP) family, which includes PP1, PP2A, PP2B, PP4, PP5, and PP7; the protein phosphatase with $\mathrm{Mg}^{2+} / \mathrm{Mn}^{2+}$ dependence (PPM), solely represented by the PP2Cs; and the DXDXT/V motif phosphatases, such as FCP1, which are specific for the
C-terminal domain (CTD) of RNA Pol II. Although the CTD stimulates $3^{\prime}$ cleavage in vitro (Hirose and Manley 1998), it does so independent of its CTD phosphorylation state (Hirose and Manley 1998; Ryan et al. 2002).

Several of the PPP family phosphatases can be specifically inhibited by low molecular weight phosphatase inhibitors. We tested a variety of these inhibitors for the ability to activate $3^{\prime}$ cleavage in vitro (Fig. 2A). At concentrations in excess of their reported $\mathrm{IC}_{50} \mathrm{~s}$ (Swingle et al. 2007), inhibitors of PP1 (Inhibitor-2), PP1/PP2A/PP4/PP5

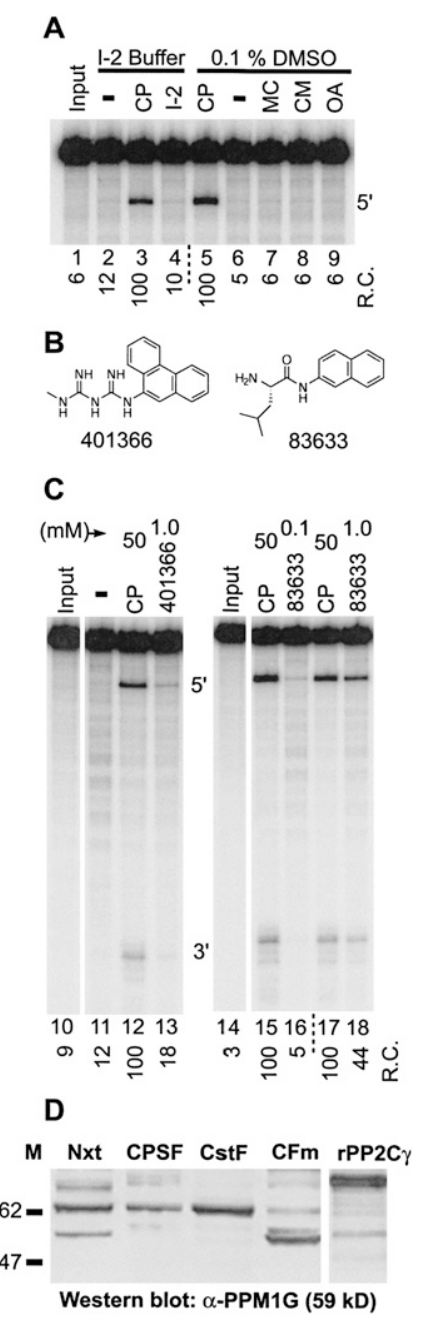

FIGURE 2. Inhibitors of PPM family phosphatases can activate $3^{\prime}$ cleavage in vitro. In vitro $3^{\prime}$ cleavage reactions were carried out as described in Figure 1 and Materials and Methods. (A) CP was replaced by inhibitors specific for various PPP family protein phosphatases to test for $3^{\prime}$ cleavage activation. (I-2) Inhibitor-2, $500 \mathrm{nM}$; (CP) creatine phosphate control, $50 \mathrm{mM}$; (MC) microcystin-LR, $500 \mathrm{nM}$; (CM) cypermethrin, $50 \mathrm{nM}$; (OA) okadaic acid, $75 \mathrm{nM}$. (B) PP2C inhibitor structures (Rogers et al. 2006). (C) Cleavage activation by PP2C inhibitors. Residual solvent concentrations were 2\% DMSO and 2\% ethanol in lanes $11-13,0.04 \%$ DMSO in lanes 15,16 , and $0.4 \%$ DMSO in lanes 17,18. Lane 18 shows cleavage activated by NCI 83633. (D) Western blot of HeLa nuclear extract (Nxt) and the DEAE-separated 3 ' cleavage factors with anti-PPM1G antibody. (rPP2C $\gamma$ ) Recombinant $\mathrm{PP} 2 \mathrm{C} \gamma$ containing a hexahistidine tag and linker $(\mathrm{mw} 66 \mathrm{kD})$. 
(okadaic acid and microcystin), and PP2B (cypermethrin) failed to activate $3^{\prime}$ cleavage in place of $\mathrm{CP}$.

The discovery of inhibitors of the PPM family of phosphatases has lagged behind that of the PPP family, but several PP2C inhibitors were recently identified (Rogers et al. 2006). Two of these, NCI 83633 and NCI 401366 (Fig. 2B), were sufficiently soluble for testing under our assay conditions. At $1 \mathrm{mM}$, compound 401366 produced lowlevel 3' cleavage (Fig. 2C, lane 13), which may be underestimated due to the high solvent concentrations required (see Materials and Methods). Compound 83633 led to a trace of cleavage at $100 \mu \mathrm{M}$, while at $1 \mathrm{mM}$ it activated $\sim 40 \%$ of the cleavage produced by $50 \mathrm{mM} \mathrm{CP}$ (Fig. 2C, lanes 14-18). Compound 83633, the 2-naphthylamide of L-leucine, is therefore the first identified $3^{\prime}$ cleavage activator that does not contain a phosphate group.

There are 18 PPM family paralogs encoded by the human genome (Lu and Wang 2008). As a class, they are expected to have similar structures and active sites (Stern et al. 2007) and would therefore be expected to share sensitivity to the same inhibitors. While several of these paralogs are known to localize to the nucleus (Moorhead et al. 2007), one in particular, PP2Cy (PPM1G), has been found to play a role in pre-mRNA splicing (Murray et al. 1999; Allemand et al. 2007), which is in turn coordinated with $3^{\prime}$ cleavage (Niwa et al. 1990; Kyburz et al. 2006; Millevoi et al. 2006). We detected PP2C $\gamma$ at varying levels by Western blotting in our partially purified cleavage factors (Fig. 2D). PPM1A and PPM1D, two other nuclear PP2Cs, were also probed and detected (not shown). The occurrence of PPM family phosphatases in our reconstituted reactions leaves open the possibility that NCI 83633 activates $3^{\prime}$ cleavage via one of these enzymes, a line of inquiry we are investigating.

In addition to its documented ability to inhibit PP2C, NCI 83633 is known to be an in vitro indicator substrate for leucine aminopeptidase (LAP) (Green et al. 1955; Umezawa et al. 1975). If the cleavage factor fractions were contaminated with aminopeptidase activity, NCI 83633 might appear to activate cleavage merely by protecting, through competitive inhibition, one or more cleavage factors from aminopeptidase degradation. We investigated this possibility by three approaches. First, we tested bestatin, a potent $\left(K_{\mathrm{i}}<20 \mathrm{nM}\right)$ inhibitor of leucine and arginine aminopeptidases (Umezawa et al. 1975; Wilkes and Prescott 1985), for the ability to stimulate $3^{\prime}$ cleavage. Bestatin failed to elicit any $3^{\prime}$ cleavage over the range of $0.01 \mu \mathrm{M}$ to $1 \mathrm{mM}$ (Fig. $3 \mathrm{~A}$ ), demonstrating that efficient aminopeptidase inhibition does not lead to an increase in cleavage. Second, we tested three strong cleavage activators-fluoride, CP, and phosphocholine (see below) - for the ability to inhibit the aminopeptidase most likely to be affected by L-83633, leucine aminopeptidase (LAP). None of these activators significantly inhibited LAP, and there was no correspondence between the ability to inhibit LAP and 3 ' cleavage activation (Fig. 3B). Third, we analyzed directly the DEAE-fractionated cleavage factors for contaminating aminopeptidase activity using the chromogenic substrate leucine p-nitroanilide (Wilkes and Prescott 1985). Compared to a standard curve generated using commercial LAP, we measured trace amounts of an aminopeptidase activity corresponding to the equivalent of $6.2 \times 10^{-3} \mathrm{u} / \mathrm{mL}$ LAP in a standard in vitro cleavage reaction. To determine whether the cleavage factors were sensitive to this amount of aminopeptidase activity, we augmented in a cleavage reaction the detected aminopeptidase activity by two-, five-, and 10-fold amounts of LAP (Fig. 3C). No significant loss in cleavage activity resulted. This experiment indicated that the cleavage factors are insensitive to aminopeptidase activity on the scale in which it occurs in our cleavage factor preparations. Aminopeptidase inhibition should therefore not increase in vitro cleavage efficiency. These control experiments rule out the possibility that 83633 activates $3^{\prime}$ cleavage by protecting the cleavage factors from a contaminating aminopeptidase activity.

A

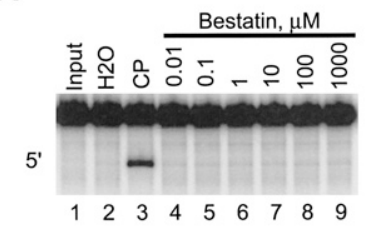

B

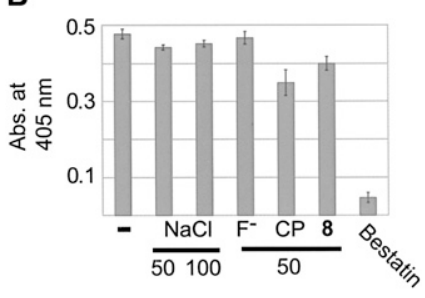

C

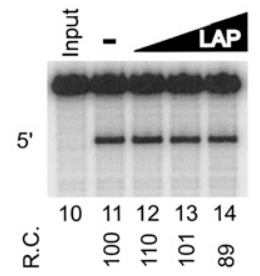

FIGURE 3. Compound 83633 does not activate $3^{\prime}$ cleavage by protecting the cleavage factors from residual HeLa aminopeptidase activity. L-83633, a PP2C inhibitor, is also a competitive inhibitor of leucine aminopeptidase (LAP). (A) Bestatin, a potent inhibitor of LAP, did not activate $3^{\prime}$ cleavage. (B) 3' Cleavage activators do not inhibit cleavage by virtue of aminopeptidase inhibition. Activators $\mathrm{F}^{-}$, $\mathrm{CP}$, and compound 8 (see below) were tested for the ability to inhibit LAP directly. Bestatin $(100 \mu \mathrm{M})$ was used as a positive control. Error bars are $\pm 1 \mathrm{SD}$. (C) Cleavage factor activity is not sensitive to aminopeptidase spiking. LAP was added directly to a standard in vitro $3^{\prime}$ cleavage reaction to test for cleavage factor sensitivity to aminopeptidase activity. Lane 12 (twofold), lane 13 (fivefold), and lane 14 (10-fold) increase in LAP with respect to the amount detected in the cleavage factors (see Materials and Methods). 


\section{Cleavage activation by L-83633 analogs}

To begin to understand the structural basis of NCI 83633's activity we tested a group of structural analogs in the $3^{\prime}$ cleavage assay (Fig. 4). Inverting the leucine side chain of NCI 83633 (L-isomer, henceforth L-83633) to D-leucine-2naphthylamide (D-83633) resulted in only a small decrease in potency at $1 \mathrm{mM}$. Removing the side chain entirely (compound 1) showed no further loss of activity, indicating that the hydrophobic side chain of 83633 contributes little to cleavage activation. Replacing leucine with arginine, the amino acid whose side chain most closely resembles CPs methylguanidino group, resulted in a more potent

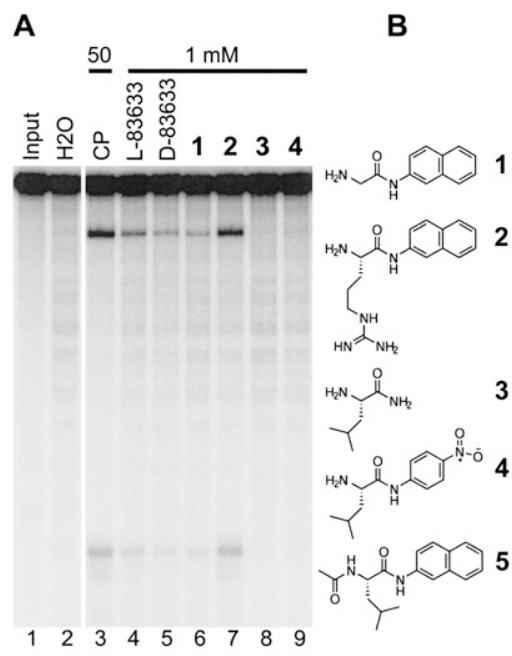

C
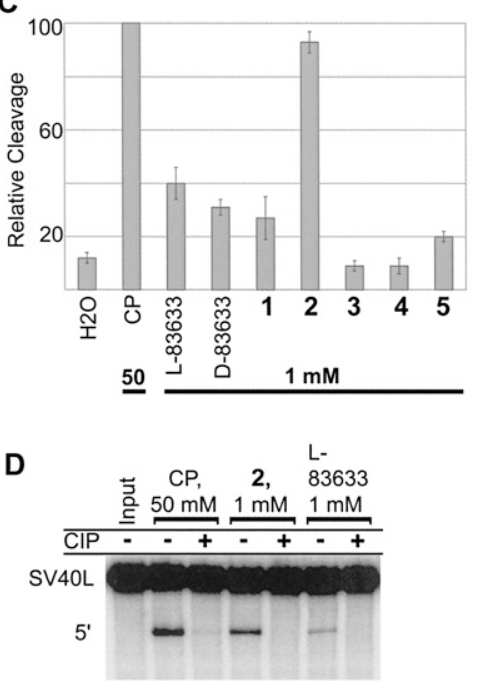

FIGURE 4. L-83633: A structure-activity study. (A) A variety of structural analogs of L-83633 were tested for the ability to activate in vitro $3^{\prime}$ cleavage at $1 \mathrm{mM}$. Standard in vitro $3^{\prime}$ cleavage reaction, as described in Figure 1. (B) Analog structures. (C) Quantitative summary of three or more independent in vitro cleavage reactions. Error bars are \pm 1 SD. $(D)$ Glycine 2-naphthylamides cannot activate in vitro $3^{\prime}$ cleavage in dephosphorylated nuclear extract. (CIP) 2-u calf intestinal alkaline phosphatase pretreatment. compound, 2, that at $1 \mathrm{mM}$ produced nearly as much $3^{\prime}$ cleavage as $50 \mathrm{mM} \mathrm{CP}$. Removal of the naphthyl group from L-83633 resulted in complete loss of activity (L-leucinamide, 3) as did replacement with the smaller phenyl ring in 4. Arginine alone did not stimulate cleavage ( $1 \mathrm{mM}$, not shown), demonstrating that the naphthyl group is needed even in the presence of the more potent arginine side chain. Removing the positive charge of 83633's amino group by $\mathrm{N}$-acetylation (compound $\mathbf{5}$ ) resulted in significantly reduced activity (Fig. 3C). These results show that the ability of this class of phosphate-free small molecules to activate $3^{\prime}$ cleavage depends on the core glycine-2naphthylamide structure, with significantly greater activity resulting from the addition of the arginine side chain.

If L-83633 and related compounds activate $3^{\prime}$ cleavage in vitro by inhibiting a cleavage-suppressing PPM phosphatase, they would not be expected to activate cleavage in a phosphatase pretreated nuclear extract, where any phosphorylated cleavage factors would have already been dephosphorylated and the extract rendered inactive (Ryan 2007). As shown in Figure 4D, the glycine naphthylamides share CPs inability to activate $3^{\prime}$ cleavage when the extract is pretreated with a nonspecific phosphatase.

\section{Phosphocholine is a more effective activator of $3^{\prime}$ cleavage than creatine phosphate}

We undertook a similar structure-activity analysis of $\mathrm{CP}$ in order to understand the determinants of its activity. $\mathrm{CP}$ and the structurally related cleavage activators phosphoserine (Hirose and Manley 1998) and arginine phosphate (Hirose and Manley 1997) each have a phosphate linked directly or closely to a positively charged amine or methylguanidino group, in addition to having a nearby carboxylic acid. We tested whether other positively charged amines linked closely to a phosphate would stimulate cleavage and also whether the carboxylate was necessary in this context. As representative phosphoamino compounds we used phosphocholine, 8, which contains a flexible two-carbon linker between the amine and phosphate, and D-glucosamine-6phosphate, 7 , in which the charged groups are kept apart by a rigid linker (Fig. 5A). Glucose-6-phosphate, 6, served as a control to assess the importance of the amine in 7 . Compounds 6 and 7 did not activate $3^{\prime}$ cleavage beyond the expected $\mathrm{Na}^{+}$effect, but phosphocholine $\mathbf{8}$ was highly effective, promoting more 3 ' cleavage than any other small molecule we have tested (Fig. 5B, lanes 1-8).

Since 8 was a much better activator of $3^{\prime}$ cleavage than CP (Fig. 5C), we switched our focus to the structural determinants of this compound's activity (Fig. 5, lanes 919). Replacing the trimethylammonium group of 8 with a primary amine, as in colamine phosphate, 11, sharply reduced activity. Interestingly, partial activity can be restored to 11 by adding a carboxylate, i.e., phosphoserine 12, which is known to be as active as CP (Hirose and 
A

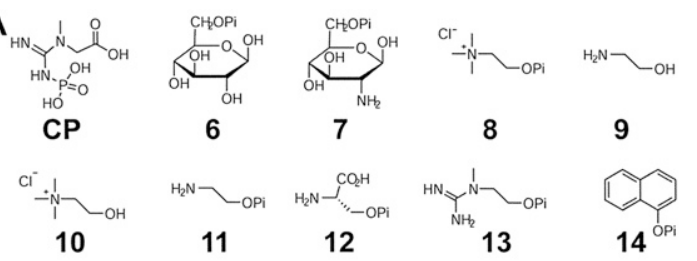

B
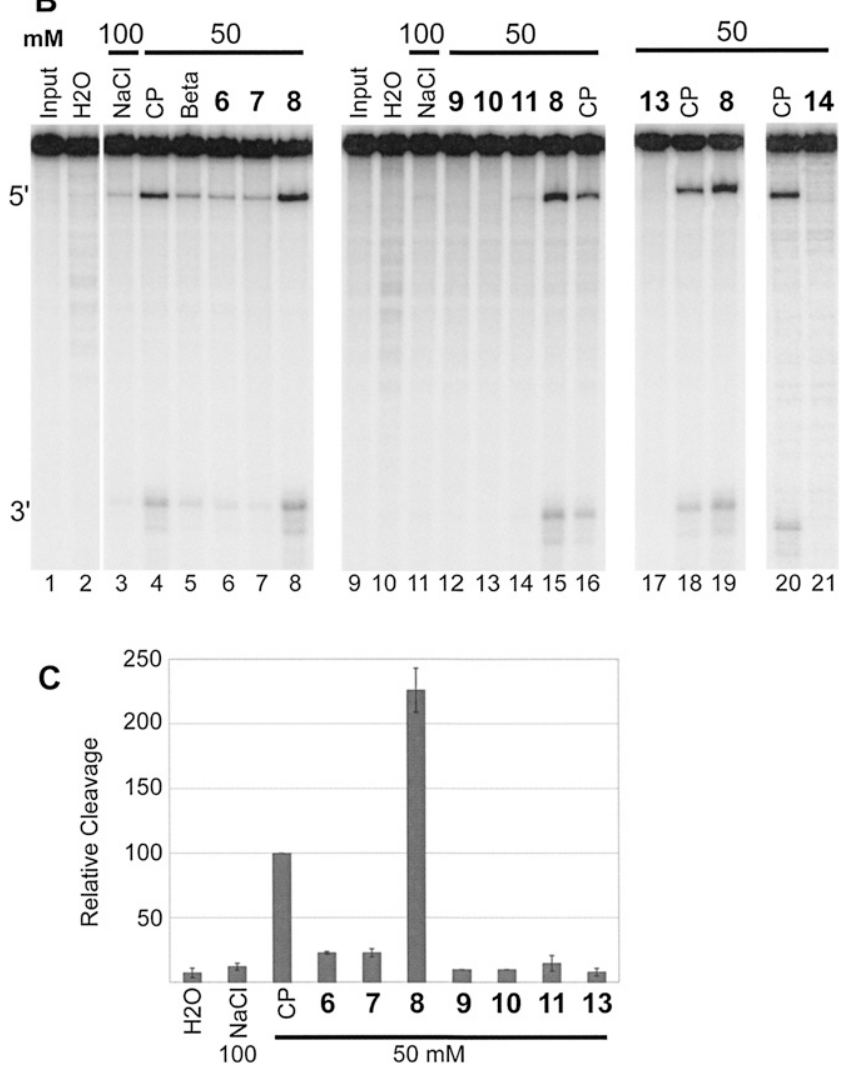

FIGURE 5. $3^{\prime}$ Cleavage activation by analogs of CP and phosphocholine. (A) Compounds used to probe the structural determinants of CP's $3^{\prime}$ cleavage activation ability, shown in neutral form with Pi indicating phosphate. (B) Representative in vitro cleavage reactions. Total $\mathrm{Na}^{+}$ held constant at $100 \mathrm{mM}$ in all reactions except lane 2. (C) Quantitative summary of three or more experiments. Error bars are \pm 1 SD. Standard in vitro $3^{\prime}$ cleavage reactions, as described in Figure 1.

Manley 1998). The carboxylate group therefore appears to be important for the activity of phosphoserine, but is not necessary in $\mathbf{8}$. Compound $\mathbf{1 0}$, choline chloride, demonstrated that the phosphate group of $\mathbf{8}$ was also required, as expected. Compound 9, which lacked both the trimethyl and phosphate groups, was inactive. The strong cleavage activation by 8 therefore requires both the phosphate and the trimethylammonium group. Unlike $\mathrm{CP}$ and phosphoserine, no carboxylate is needed.

The positively charged trimethylammonium group of $\mathbf{8}$ and the methylguanidino group of $\mathrm{CP}$ are similar in that they both have a positive charge that is partially spread over several atoms, three methyl groups or three nitrogens, respectively. The charged groups have very different shapes, roughly spherical in the former and planar in the latter. We tested whether the methylguanidino group could replace the trimethylammonium group of $\mathbf{8}$. The compound incorporating this change, creatinol-O-phosphate, 13 , was inactive (Fig. 5), indicating that the groups are not interchangeable. Thus, the three-dimensional shapes of these groups appear critical, though they are identically charged.

1-Naphthyl phosphate (Pondaven and Meijer 1986; Zollner 1999), 14, a known acid phosphatase inhibitor that combines the naphthyl and phosphate functional groups, was also tested. Despite the importance of these two groups to cleavage activation by $\mathrm{CP}, \mathbf{8}$, and the glycinenaphthylamides, their combination in $\mathbf{1 4}$ did not activate 3 ' cleavage (Fig. 5B, lanes 20,21). Activation of $3^{\prime}$ cleavage therefore appears to be just as dependent on the specific arrangement of favorable functional groups within an activator as on the nature of the functional groups. This observation argues more for a specific small moleculeprotein interaction as the origin of the cleavage activation than for a general ionic or hydrophobic effect, despite the relatively high concentrations needed for activation by these compounds.

To judge the effectiveness of compounds $\mathbf{2}$ and $\mathbf{8}$ relative to $\mathrm{CP}$ we compared the three side by side (Fig. 6). Compound 2 activated detectable $3^{\prime}$ cleavage at $200 \mu \mathrm{M}$ (Fig. 6, lane 13), a concentration close to the threshold at which L-83633 showed activity (Fig. 2C) and close to the approximate $\mathrm{IC}_{50}$ of L-83633 for PP2C (Rogers et al. 2006). Compound 2's threshold for activating cleavage is therefore 50 -fold lower than the $10 \mathrm{mM}$ concentration required by $\mathrm{CP}$ and $\mathbf{8}$ for comparable activity (Fig. 6). At the next higher concentration tested, the 50-fold difference continued

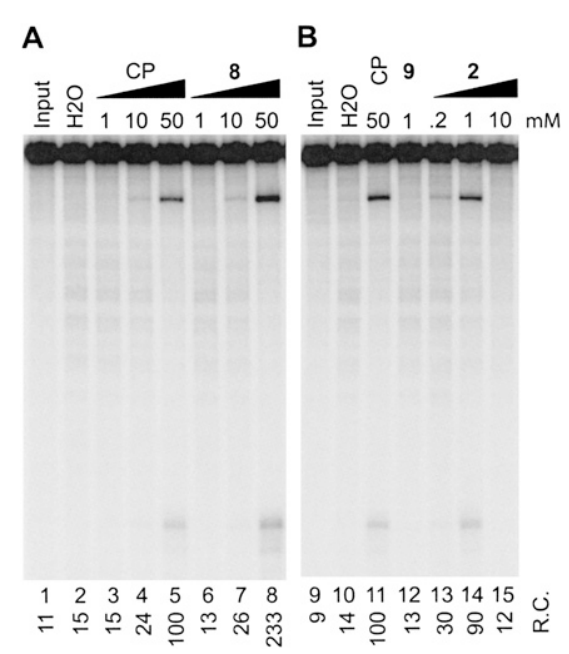

FIGURE 6. $3^{\prime}$ Cleavage activation threshold and potency. A comparison of $\mathrm{CP}$ with phosphocholine, $\mathbf{8}$ and arginine-2-naphthylamide 2. CP compared to $\mathbf{8}(A)$ and $\mathbf{2}(B)$ at increasing concentrations. Phosphocholine, $\mathbf{8}$ activated the most $3^{\prime}$ cleavage, but $\mathbf{2}$ is the strongest activator at low concentration. Relative cleavage (R.C.) numbers above gel lanes indicate activator concentration, in millimolar. 
to hold, as $1 \mathrm{mM}$ compound 2 was about as effective as 50 $\mathrm{mM}$ CP. When the concentration of 2 was raised to $10 \mathrm{mM}$, however, it lost activity, perhaps due to intolerance by the cleavage factors of high concentrations of hydrophobic compounds. (DMSO was found to inhibit cleavage as well; see Materials and Methods.) As noted earlier, at $50 \mathrm{mM}, 8$ is more than twice as effective as CP. Thus, naphthylamides 2 and L-83633 have the lowest threshold for activity, while 8 stimulates more cleavage than all other compounds tested, each at their highest concentration, including fluoride, whose high solubility allowed $100 \mathrm{mM}$ to be tested, where it surpassed $50 \mathrm{mM} \mathrm{CP}$.

\section{DISCUSSION}

The in vitro study of human pre-mRNA $3^{\prime}$ processing is hampered by the large number of protein factors involved, almost all of which must be extracted from human cells, and at least one of which, CFIIm, remains incompletely characterized (de Vries et al. 2000). With the exception of CFIm (Rüegsegger et al. 1998), recombinant 3' cleavage factors cannot be used to reconstitute the reaction in vitro. The development of small-molecule agents that affect $3^{\prime}$ processing, through either activation or inhibition, may lead to much needed chemical tools for pre-mRNA processing studies. CP and the related phosphoamino acids phosphoserine and arginine phosphate are the only smallmolecule reagents known to have an activating effect on the in vitro cleavage reaction. No specific inhibitors of the cleavage reaction have been reported, though a natural product inhibitor of polyadenylation was recently discovered (Jiang et al. 2008; Parish et al. 2008).

Although CP has been used for many years to activate $3^{\prime}$ cleavage in vitro, the way in which it works is unknown. Its effect is likely peculiar to the transcription-independent reaction because $\mathrm{CP}$ is not required in the more natural context of transcription-coupled in vitro cleavage (Adamson et al. 2005). CP has been suggested to work by mimicking the role of a phosphoprotein, namely, the Pol II CTD, a domain that undergoes extensive phosphorylation cycles during transcription. This suggestion led to the discovery that the Pol II CTD can stimulate 3' cleavage (Hirose and Manley 1998). Because the recombinant CTD was found to activate cleavage even when completely unphosphorylated, it is improbable that CP functions as a phospho-CTD mimic, leaving unanswered the question of how CP works.

We previously modified the phosphoprotein mimic hypothesis by proposing that at high concentrations $\mathrm{CP}$ might nonspecifically compete for, and interfere with, a phosphoprotein binding protein such as a protein phosphatase (Ryan 2007). If the phosphatase were inhibitory, then CP might relieve this inhibition and activate cleavage. Such a phosphatase could conceivably function cotranscriptionally as a switch to suppress $3^{\prime}$ cleavage at cryptic polyadenylation sites encountered upstream of the $3^{\prime}$ UTR during transcription or under other inauthentic circumstances (Ryan and Bauer 2008). This model led us to test a variety of established S/T phosphatase inhibitors in the $3^{\prime}$ cleavage reaction. If an inauthentic cleavage context, such as the absence of transcription, causes the putative phosphatase to dephosphorylate one of the cleavage factors and thereby inhibit its activity, then including a phosphatase inhibitor in the reaction may preserve the phospho form of the cleavage factor and enable cleavage to occur in vitro. We have shown here that two phosphatase inhibitors, fluoride/EDTA, a general S/T phosphatase inhibitor, and NCI 83633 (leucine-2-napthylamide), a PP2C inhibitor (Rogers et al. 2006), stimulate $3^{\prime}$ cleavage in vitro.

The finding that fluoride activates cleavage is consistent with our previous observation that S/T phosphatases, but not tyrosine phosphatases, inhibit HeLa 3' cleavage activity in vitro (Ryan 2007). The concentration of fluoride needed to activate cleavage is in the range that is typically used to inhibit S/T phosphatases. Fluoride inhibits S/T phosphatases either by dislodging a metal cofactor (Mackenzie III et al. 1980) or by altering the phosphatase conformation allosterically (Shacter-Noiman and Chock 1983). While S/T phosphatases, including those of the PPM family, generally require a divalent metal cofactor, our cleavage reactions are carried out in the presence of $2 \mathrm{mM}$ EDTA, a condition under which phosphatases with loosely bound metal cofactors should not be active. Two of the CPSF subunits, CPSF-30 and CPSF-73, are themselves metalloproteins, yet they remain functional in the presence of EDTA. A phosphatase with tightly bound divalent cations could likewise remain active were one to copurify with the cleavage factor preparations we have used. Alternatively, a phosphatase might negatively affect $3^{\prime}$ cleavage by direct interference in a precleavage complex, irrespective of its catalytic activity, and be counteracted allosterically by fluoride or other small molecule inhibitors.

The finding that the PP2C inhibitor L-83633 activates 3' cleavage also supports the hypothesis that a $\mathrm{S} / \mathrm{T}$ phosphatase negatively affects $3^{\prime}$ cleavage and suggests more specifically the involvement of a PPM family phosphatase. The members of this family of S/T phosphatases are involved in a wide variety of physiological processes, ranging from stress signaling cascades to ubiquitination and pre-mRNA splicing (Lu and Wang 2008). The PPM family of phosphatases is known to be inhibited by fluoride (Moore et al. 1991). The threshold concentration for cleavage activation by L-83633 and 2 (100-200 $\mu \mathrm{M})$ is approximately the same as L-83633's $\mathrm{IC}_{50}$ for PP2C $\alpha$, as estimated previously in vitro (Rogers et al. 2006). Although this $\mathrm{IC}_{50}$ indicates weak inhibition, L-83633 has only been tested against PP2C $\alpha$ and may be more potent against other members of the PPM family, one of which, PP2C $\gamma$, is involved in pre-mRNA splicing (Murray et al. 1999). The inability of the PPP family phosphatase inhibitors to activate cleavage (Fig. 2A) provides additional confidence 
that the effects of L-83633 and fluoride are indicative of PPM, and not PPP, phosphatase involvement in 3 ' cleavage suppression. The fact that there are 18 PPM phosphatases makes it difficult to choose at this stage a particular PPM phosphatase for knockdown or overexpression studies.

Regardless of which phosphatase is affected, the amino acid-2-napthylamides are important for being the first nonphosphate-containing organic compounds found to activate 3 ' cleavage. They are structurally simple, and it will be straightforward to extend our structure-activity studies in search of a more potent analog. In contrast, CP is difficult to manipulate synthetically, is highly charged, and has a 50fold higher threshold of activation than 2 and L-83633.

Phosphocholine, 8, and glucosamine-6-phosphate, 7, were assayed in place of CP to test the idea that CPs minimal cleavage-activating structural feature might be the proximity of an amine $(+1$ charge $)$ and phosphate $(-2$ charge $)$ in a small molecule. Phosphocholine, $\mathbf{8}$ has a flexible linker of two carbons, and 7 has a rigid glucose linker that keeps the two oppositely charged groups apart. Compound 7 was inactive, but 8 was more active than even CP. Phosphocholine is a biosynthetic intermediate and breakdown product of phosphatidylcholine, an important membrane phosphospholipid. Its intracellular concentration is $\sim 1.1 \mathrm{mM}$ (Choy et al. 1978; Zhu et al. 2003), and rises to $\sim 3 \mathrm{mM}$ in cancer cells (Glunde et al. 2004). These values are below the threshold for cleavage activation in our in vitro assay. Like CP (Hirose and Manley 1997), phosphocholine is therefore probably not a natural cofactor of the 3 ' cleavage reaction, but stimulates $3^{\prime}$ cleavage serendipitously. The dominating structural feature responsible for this activity in $\mathrm{CP}$ and $\mathbf{8}$ is the close positioning of a positively charged amine and a phosphate in the same molecule. As compounds 11 and 13 show, this feature is not sufficient in all structural contexts. In particular, 13 shows that the spherical trimethylammonium group of $\mathbf{8}$ cannot be replaced by the planar methylguanidino group of CP.

The results presented here lead to a list of functional groups that are found in small molecules that activate in vitro 3' cleavage: phosphomonoester, guanidino, methylphosphoguanidino, naphthyl, trimethylalkylammonium, and carboxylate. No single group is sufficient, and the ability to activate pre-mRNA cleavage in vitro is highly sensitive to the relative positioning of these groups within the small molecule activators. This trend supports the possibility that cleavage activation is caused by a specific small molecule-protein interaction, as opposed to a nonspecific salt or hydrophobic effect. Although CP and the glycine 2-naphthylamides are quite different, it is common in small molecule-protein interactions for widely differing structures to bind the same protein. For example, aspirin, arachidonic acid, and Vioxx all bind the cyclooxygenase 2 active site. The PP2C inhibitor L-83633 provides a link between $3^{\prime}$ processing and the PPM family of phosphatases, and suggests that a member of this family is involved in the small molecule-protein interaction proposed here, and plays a negative regulatory role in premRNA 3' processing.

\section{MATERIALS AND METHODS}

\section{Chemicals and enzymes}

The following PP2C inhibitors (Rogers et al. 2006) were obtained from the NIH NCI Developmental Therapeutics Program: 83633, 401366, 12155, 127153, and 109268. CP, microcystin, cypermethrin, and okadaic acid (Calbiochem); Inhibitor-2 (New England Biolabs); bestatin (USB); 1, 7, and porcine kidney leucine aminopeptidase (Sigma-Aldrich); $2-4$ and $83633 \bullet \mathrm{HCl}$ (Bachem); 6 (MP Biomedicals); 8 (TCI); 9 (Research Organics); 10 and 14 (Alfa Aesar); 11 (Fluka); and 13 (Chromadex). CP, phosphate (Pi), pyrophosphate (PiPi), $\beta$-phosphoglycerol, 6, 7, 8, 11, 13, 14, and tartrate were all used as disodium salts. Compound $\mathbf{5}$ was made by stirring $0.8 \mathrm{mmol}$ of the free base of L-83633 with $1.04 \mathrm{mmol}$ of acetic anhydride and $1.04 \mathrm{mmol}$ triethylamine in $3 \mathrm{~mL}$ methylene chloride at room temperature overnight, evaporating it, and recrystallizing from acetonitrile. It was verified by ${ }^{1} \mathrm{H}-\mathrm{NMR}$ and thin layer chromatography. The melting point was $178^{\circ} \mathrm{C}-180^{\circ} \mathrm{C}$.

\section{Activator stock solutions}

Free-base 83633 was dissolved in DMSO $(250 \mathrm{mM})$, then serially diluted in water. When $83633 \bullet \mathrm{HCl}$ salt was used the stock was made fresh in pure water just prior to use. 401366 was dissolved at $20 \mathrm{mM}$ in $40 \% \mathrm{DMSO} / 40 \%$ ethanol, leading to $2 \%$ final DMSO and ethanol. These solvents inhibited CP-activated cleavage by $45 \%$ compared to $0.4 \%$ DMSO, so the activity of 401366 is likely underestimated in Figure 2. 12155 and 127153 could not be solubilized in the cleavage reaction conditions at $1 \mathrm{mM}$ without prohibitively high DMSO concentrations. 109268 could not be dissolved in any solvent. All 2-napthylamide $\bullet \mathrm{HCl}$ salts and phosphate salts were dissolved in water. PPP inhibitors (microcystin, cypermethrin, and okadaic acid) were dissolved in pure DMSO and serially diluted in water. Inhibitor-2 was diluted in Buffer D50AS (see below). In addition to Figure 2A, the PPP inhibitors were also found inactive at the following concentrations (not shown): OA (150 nM), microcystin (20 nM), and cypermethrin $(10 \mathrm{nM})$.

\section{Buffers}

Buffer D50AS consisted of 20\% glycerol, $20 \mathrm{mM}$ HEPES-NaOH (pH 7.9), $0.2 \mathrm{mM}$ EDTA, $0.2 \mathrm{mM}$ PMSF, $0.5 \mathrm{mM}$ DTT, and 50 $\mathrm{mM}$ ammonium sulfate.

\section{HeLa cleavage factor preparation}

HeLa cells were purchased from the National Cell Culture Center (Biovest International). Nuclear extract preparation was performed as previously described (Ryan 2007). The extract was fractionated on DEAE-Sepharose also as previously described (Ryan 2007), based on established methods (Gilmartin et al. 1988; Takagaki et al. 1989; Ryan et al. 2002). Cleavage factor fractions were concentrated by ammonium sulfate precipitation and dialyzed thoroughly at $4^{\circ} \mathrm{C}$ in Buffer D50AS. For the factors 
used in these experiments the optimized ratio of cleavage factors (and total protein by Bio-Rad Bradford protein assay vs. BSA) was CPSF $(5 \mathrm{mg} / \mathrm{mL}) / \mathrm{CstF}(7 \mathrm{mg} / \mathrm{mL}) / \mathrm{CFm}(8 \mathrm{mg} / \mathrm{mL})=0.4 / 0.2 / 0.5$ $\mu \mathrm{L}$ per $12.5 \mu \mathrm{L}$ processing reaction. All three fractions were required for $3^{\prime}$ cleavage.

\section{RNA substrate}

SV40 late pre-mRNA (233 nt) was transcribed from the pG3SVL-A plasmid linearized at the DraI site (Takagaki et al. 1988). Substrate RNA was uniformly labeled by including $\left[\alpha-{ }^{32} \mathrm{P}\right]$-UTP (PerkinElmer Life Sciences) and 5' capped during transcription (cap analog; New England Biolabs).

\section{In vitro 3' cleavage reactions}

Cleavage reactions were carried out as previously described (Ryan 2007) in $12.5 \mu \mathrm{L}$ and contained, in addition to the cleavage activators indicated in the figures, tRNA $(0.1 \mathrm{mg} / \mathrm{mL})$, EDTA $(2$ $\mathrm{mM}), 2^{\prime}$-dATP (2 mM), DTT (0.41 mM), BSA (Roche; $\left.40 \mathrm{ng} / \mu \mathrm{L}\right)$, placental RNase inhibitor (Promega, $0.32 \mathrm{u} / \mu \mathrm{L}$ ), polyvinyl alcohol (2.5\%), 10\% glycerol, $10 \mathrm{mM}$ HEPES-NaOH (pH 7.9), $25 \mathrm{mM}$ ammonium sulfate, the cleavage factors described above, and the RNA substrate $(1-5 \mathrm{nM})$. The reactions were left at $30^{\circ} \mathrm{C}$ for $2 \mathrm{~h}$ and then digested with Proteinase $\mathrm{K}$, phenol- $\mathrm{CHCl}_{3}$ extracted, ethanol precipitated, and resolved on a $6 \%$ denaturing polyacrylamide gel. After drying, the gel was exposed to a Molecular Dynamics Storm PhosphorImager screen overnight and the bands quantitated using ImageQuant software. Relative cleavage (R.C.) was calculated as [5' fragment/(5' fragment + uncleaved RNA $)] \times$ 100. In each individual experiment the R.C. activated by $50 \mathrm{mM}$ CP was set to 100 . Note bestatin is a "slow-acting" inhibitor, and at low concentrations $(0.1 \mu \mathrm{M})$ and short assay times (5-10 min) its activity is not fully attained (Umezawa et al. 1975). To preserve cleavage factor activity the bestatin was not preincubated with the factors. The high bestatin concentration (up to $1 \mathrm{mM}$ ) and the 2-h processing reaction time rendered preincubation unnecessary (Fig. 3B). Stock solutions of disodium salts had a $\mathrm{pH}$ of 8-10. Scaled-up mock reactions were made for all activators and the reaction $\mathrm{pH}$ estimated using $\mathrm{pH}$ paper to be $\sim 8$. (Free acids led to low $\mathrm{pH}$ and reduced cleavage, so they were not used.)

\section{Leucine aminopeptidase (LAP, Sigma \#L5006) inhibition assay}

Three cleavage activators- $\mathrm{CP}, \mathrm{F}^{-}$, and 8 -were tested for the ability to inhibit LAP in order to assess whether they might activate $3^{\prime}$ cleavage trivially by this means. LAP activity was assayed according to the manufacturer's protocol using leucine p-nitroanilide as the substrate except that $50 \mathrm{mM}$ HEPES-Na $(\mathrm{pH}$ 7.9) was used as the buffer. Triplicate reactions including LAP were run for $20 \mathrm{~min}$ at $30^{\circ} \mathrm{C}$. Bestatin $(100 \mu \mathrm{M}$, no preincubation with LAP) was included as a positive control. The absorbance at $405 \mathrm{~nm}$ was then measured. Units were as described in the manufacturer's protocol.

\section{Aminopeptidase activity estimation in cleavage factors fractions}

LAP was diluted serially and assayed with leucine-p-nitroanilide for $2 \mathrm{~h}$ but otherwise as described above in order to construct a plot of absorbance vs. LAP activity in units per milliliter. Sufficient cleavage factors for four cleavage reactions were pooled and assayed for $2 \mathrm{~h}$ with leucine-p-nitroanilide and compared to the LAP concentration curve to estimate aminopeptidase activity (as LAP) in the factors. In this way, we estimated that a typical $12.5 \mu \mathrm{L}$ cleavage reaction using the factors described above contains the equivalent of $6.2 \times 10^{-3}$ units $/ \mathrm{mL}\left(\sim 8 \times 10^{-11} \mathrm{M}\right)$ of LAP activity. For Figure $3 \mathrm{C}, 1 \times, 5 \times$, and $10 \times$ this amount of LAP was added in $1 \mu \mathrm{L}$ to standard $12.5 \mu \mathrm{L}$ in vitro cleavage reactions, without effect.

\section{Nuclear extract dephosphorylation}

This was performed using calf intestinal alkaline phosphatase (CIP; Promega) as previously described (Ryan 2007).

\section{Western blotting}

HeLa cell nuclear extract or the DEAE-purified cleavage factors, at three times the amount typically used in a $12.5-\mu \mathrm{L}$ cleavage reaction (Ryan 2007), were separated on a $10 \%$ polyacrylamideSDS gel, transferred to nitrocellulose, and probed with $\alpha$-PPM1G from Bethyl Labs (Cat. \# A300-880A). Recombinant PPM1G (IMAGE clone 350527) was subcloned into and expressed in Escherichia coli from a pET expression vector containing a Cterminal hexahistidine tag.

\section{ACKNOWLEDGMENTS}

This work was funded by the City College of New York Science Division and NIH Award No. 1SC1GM083754-01A1 to K.R. Additional support was provided by the City College Research Centers in Minority Institutions (RCMI) grant. We thank the NIH NCI Developmental Therapeutics Program, Division of Cancer Treatment and Diagnosis, for the Diversity Set PP2C $\alpha$ inhibitors. A.K. is an undergraduate researcher supported by the Howard Hughes Medical Institute education program at CCNY. J.P. acknowledges support from the CCNY Work Study Program. We thank Professor A. Nairn for helpful discussions.

Received July 9, 2008; accepted December 8, 2008.

\section{REFERENCES}

Adamson, T.E., Shutt, D.C., and Price, D.H. 2005. Functional coupling of cleavage and polyadenylation with transcription of mRNA. J. Biol. Chem. 280: 32262-32271.

Allemand, E., Hastings, M.L., Murray, M.V., Myers, M.P., and Krainer, A.R. 2007. Alternative splicing regulation by interaction of phosphatase PP2C $\gamma$ with nucleic acid-binding protein YB-1. Nat. Struct. Mol. Biol. 14: 630-638.

Bentley, D. 2002. The mRNA assembly line: Transcription and processing machines in the same factory. Curr. Opin. Cell Biol. 14: $336-342$.

Brautigan, D.L. and Shriner, C.L. 1988. Methods to distinguish various types of protein phosphatase activity. Methods Enzymol. 159: 339-346.

Choy, P.C., Whitehead, F.W., and Vance, D.E. 1978. A rapid method for the determination of CTP and phosphocholine in rat liver and baby hamster kidney 21 cells. Can. J. Biochem. 56: 831-835.

Dantonel, J.C., Murthy, K.G., Manley, J.L., and Tora, L. 1997. Transcription factor TFIID recruits factor CPSF for formation of $3^{\prime}$ end of mRNA. Nature 389: 399-402. 
de Vries, H., Rüegsegger, U., Hubner, W., Friedlein, A., Langen, H., and Keller, W. 2000. Human pre-mRNA cleavage factor $\mathrm{II}_{\mathrm{m}}$ contains homologs of yeast proteins and bridges two other cleavage factors. EMBO J. 19: 5895-5904.

Foulkes, J.G., Erikson, E., and Erikson, R.L. 1983. Separation of multiple phosphotyrosyl-and phosphoseryl-protein phosphatases from chicken brain. J. Biol. Chem. 258: 431-438.

Gilmartin, G.M., McDevitt, M.A., and Nevins, J.R. 1988. Multiple factors are required for specific RNA cleavage at a poly(A) addition site. Genes \& Dev. 2: 578-587.

Glover-Cutter, K., Kim, S., Espinosa, J., and Bentley, D.L. 2008. RNA polymerase II pauses and associates with pre-mRNA processing factors at both ends of genes. Nat. Struct. Mol. Biol. 15: 71-78.

Glunde, K., Jie, C., and Bhujwalla, Z.M. 2004. Molecular causes of the aberrant choline phospholipid metabolism in breast cancer. Cancer Res. 64: 4270-4276.

Glusman, G., Qin, S., El-Gewely, M.R., Siegel, A.F., Roach, J.C., Hood, L., and Smit, A.F. 2006. A third approach to gene prediction suggests thousands of additional human transcribed regions. PLoS Comput. Biol. 2: e18. doi: 10.1371/journal.pcbi. 0020018.

Green, N.M., Tsou, K.-C., Bressler, R., and Seligman, A.M. 1955. The colorimetric determination of leucine aminopeptidase activity with L-leucyl- $\beta$-naphthylamide hydrochloride. Arch. Biochem. Biophys. 57: 458-474.

Hirose, Y. and Manley, J.L. 1997. Creatine phosphate, not ATP, is required for $3^{\prime}$ end cleavage of mammalian pre-mRNA in vitro. J. Biol. Chem. 272: 29636-29642.

Hirose, Y. and Manley, J.L. 1998. RNA polymerase II is an essential mRNA polyadenylation factor. Nature 395: 93-96.

Jiang, B., Xu, D., Allocco, J., Parish, C., Davison, J., Veillette, K., Sillaots, S., Hu, W., Rodriguez-Suarez, R., Trosok, S., et al. 2008. PAP inhibitor with in vivo efficacy identified by Candida albicans genetic profiling of natural products. Chem. Biol. 15: 363-374.

Kyburz, A., Friedlein, A., Langen, H., and Keller, W. 2006. Direct interactions between subunits of CPSF and the U2 snRNP contribute to the coupling of pre-mRNA $3^{\prime}$ end processing and splicing. Mol. Cell 23: 195-205.

Lu, G. and Wang, Y. 2008. Functional diversity of mammalian type $2 \mathrm{C}$ protein phosphatase isoforms: New tales from an old family. Clin. Exp. Pharmacol. Physiol. 35: 107-112.

Mackenzie III., C.W., Bulbulian, G.J., and Bishop, J.S. 1980. Use of fluoride to inactivate phosphorylase a phosphatases from rat liver cytosol. Presence of fluoride-insensitive glycogen synthase-specific phosphatase. Biochim. Biophys. Acta 614: 413-424.

Mandel, C.R., Kaneko, S., Zhang, H., Gebauer, D., Vethantham, V., Manley, J.L., and Tong, L. 2006. Polyadenylation factor CPSF-73 is the pre-mRNA 3'-end-processing endonuclease. Nature 444: 953 956.

Mandel, C.R., Bai, Y., and Tong, L. 2007. Protein factors in premRNA 3'-end processing. Cell. Mol. Life Sci. 65: 1099-1122.

Millevoi, S., Loulergue, C., Dettwiler, S., Karaa, S.Z., Keller, W., Antoniou, M., and Vagner, S. 2006. An interaction between U2AF 65 and $C F I_{m}$ links the splicing and $3^{\prime}$ end processing machineries. EMBO J. 25: 4854-4864.

Moore, C.L. and Sharp, P.A. 1985. Accurate cleavage and polyadenylation of exogenous RNA substrate. Cell 41: 845-855.

Moore, F., Weekes, J., and Hardie, D.G. 1991. Evidence that AMP triggers phosphorylation as well as direct allosteric activation of rat liver AMP-activated protein kinase. A sensitive mechanism to protect the cell against ATP depletion. Eur. J. Biochem. 199: 691-697.

Moorhead, G.B., Trinkle-Mulcahy, L., and Ulke-Lemee, A. 2007. Emerging roles of nuclear protein phosphatases. Nat. Rev. Mol. Cell Biol. 8: 234-244.

Murray, M.V., Kobayashi, R., and Krainer, A.R. 1999. The type 2C Ser/Thr phosphatase PP2Cy is a pre-mRNA splicing factor. Genes \& Dev. 13: 87-97.
Neugebauer, K.M. 2002. On the importance of being co-transcriptional. J. Cell Sci. 115: 3865-3871.

Niwa, M., Rose, S.D., and Berget, S.M. 1990. In vitro polyadenylation is stimulated by the presence of an upstream intron. Genes \& Dev. 4: $1552-1559$.

Parish, C.A., Smith, S.K., Calati, K., Zink, D., Wilson, K., Roemer, T., Jiang, B., Xu, D., Bills, G., Platas, G., et al. 2008. Isolation and structure elucidation of parnafungins, antifungal natural products that inhibit mRNA polyadenylation. J. Am. Chem. Soc. 130: 7060-7066.

Pondaven, P. and Meijer, L. 1986. Protein phosphorylation and oocyte maturation. I. Induction of starfish oocyte maturation by intracellular microinjection of a phosphatase inhibitor, $\alpha$-naphthylphosphate. Exp. Cell Res. 163: 477-488.

Rogers, J.P., Beuscher, A.E., Flajolet, M., McAvoy, T., Nairn, A.C., Olson, A.J., and Greengard, P. 2006. Discovery of protein phosphatase 2C inhibitors by virtual screening. J. Med. Chem. 49: $1658-1667$.

Rüegsegger, U., Blank, D., and Keller, W. 1998. Human pre-mRNA cleavage factor $\mathrm{I}_{\mathrm{m}}$ is related to spliceosomal SR proteins and can be reconstituted in vitro from recombinant subunits. Mol. Cell 1: 243-253.

Ryan, K. 2007. Pre-mRNA 3' cleavage is reversibly inhibited in vitro by cleavage factor dephosphorylation. RNA Biol. 4: 26-33.

Ryan, K. and Bauer, D.L 2008. Finishing touches: Post-translational modification of protein factors involved in mammalian premRNA 3' end formation. Int. J. Biochem. Cell Biol. 40: 2384-2396.

Ryan, K., Murthy, K.G., Kaneko, S., and Manley, J.L. 2002. Requirements of the RNA polymerase II C-terminal domain for reconstituting pre-mRNA 3' cleavage. Mol. Cell. Biol. 22: 1684-1692.

Shacter-Noiman, E. and Chock, P.B. 1983. Properties of a $\mathrm{Mr}=$ 38,000 phosphoprotein phosphatase. Modulation by divalent cations, ATP, and fluoride. J. Biol. Chem. 258: 4214-4219.

Shenolikar, S. 2001. Detection of phosphorylation by enzymatic techniques. In Current Protocols in Molecular Biology: Unit18.5. Wiley, Hoboken, NJ.

Stern, A., Privman, E., Rasis, M., Lavi, S., and Pupko, T. 2007. Evolution of the metazoan protein phosphatase 2C superfamily. J. Mol. Evol. 64: 61-70.

Swingle, M., Ni, L., and Honkanen, R.E. 2007. Small-molecule inhibitors of ser/thr protein phosphatases: Specificity, use and common forms of abuse. Methods Mol. Biol. 365: 23-38.

Takagaki, Y., Ryner, L.C., and Manley, J.L. 1988. Separation and characterization of a poly(A) polymerase and a cleavage/specificity factor required for pre-mRNA polyadenylation. Cell 52: 731-742.

Takagaki, Y., Ryner, L.C., and Manley, J.L. 1989. Four factors are required for 3'-end cleavage of pre-mRNAs. Genes \& Dev. 3: 1711-1724.

Umezawa, H., Aoyagi, T., Suda, H., Hamada, M., and Takeuchi, T. 1975. Bestatin, an inhibitor of aminopeptidase B, produced by actinomecetes. J. Antibiotics (Tokyo) 29: 97-99.

Venkataraman, K., Brown, K.M., and Gilmartin, G.M. 2005. Analysis of a noncanonical poly(A) site reveals a tripartite mechanism for vertebrate poly $(\mathrm{A})$ site recognition. Genes \& Dev. 19: 1315-1327.

Wilkes, S.H. and Prescott, J.M. 1985. The slow, tight binding of bestatin and amastatin to aminopeptidases. J. Biol. Chem. 260: 13154-13162.

Zhao, J., Hyman, L., and Moore, C. 1999. Formation of mRNA 3' ends in eukaryotes: Mechanism, regulation, and interrelationships with other steps in mRNA synthesis. Microbiol. Mol. Biol. Rev. 63: $405-445$.

Zhu, X., Song, J., Mar, M.H., Edwards, L.J., and Zeisel, S.H. 2003. Phosphatidylethanolamine N-methyltransferase (PEMT) knockout mice have hepatic steatosis and abnormal hepatic choline metabolite concentrations despite ingesting a recommended dietary intake of choline. Biochem. J. 370: 987-993.

Zollner, H. 1999. Handbook of enzyme inhibitors. In Wiley-VCH, Weinheim, Germany. 

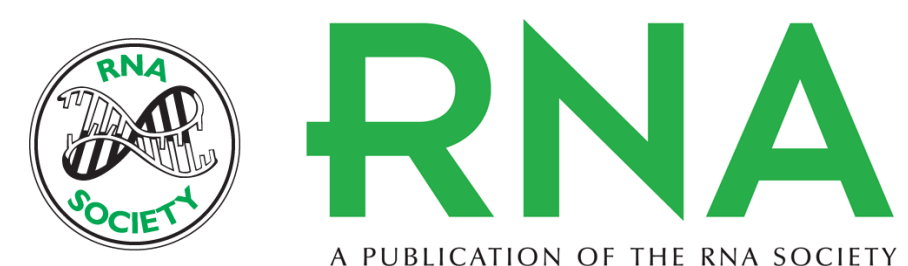

A PUBLICATION OF THE RNA SOCIETY

\section{Small molecule activators of pre-mRNA 3' cleavage}

Kevin Ryan, Asya Khleborodova, Jingyi Pan, et al.

RNA 2009 15: 483-492 originally published online January 20, 2009

Access the most recent version at doi:10.1261/rna.1262509

\section{References This article cites 45 articles, 15 of which can be accessed free at: http://rnajournal.cshlp.org/content/15/3/483.full.html\#ref-list-1}

Open Access Freely available online through the RNA Open Access option.

License Freely available online through the open access option.

Email Alerting Receive free email alerts when new articles cite this article - sign up in the box at the Service top right corner of the article or click here. 